\title{
CARACTERIZAÇÃO AMBIENTAL E EVOLUÇÃO ESPAÇO/TEMPORAL DAS FEIÇÕES MORFOLÓGICAS DO RIO PARAGUAI NO SEGMENTO ENTRE A FOZ DO CÓRREGO JACOBINA A BAÍA DOS PESTIADOS, CÁCERES - MT.
}

\author{
Vinicius Neves daSilva ${ }^{(a)}$; Célia Alves de Souza ${ }^{(b)}$; Willian Cosme da Silveira de \\ Paula $^{(\mathrm{c})} ;$ Josiane São Bernardo da Cruz $^{(\mathrm{d})}$
}

\begin{abstract}
${ }^{(a, b, c, d)}$ Departamento de Geografia/Faculdade de Ciências Humanas, UNEMAT - Universidade do Estado de Mato Grosso, (E-mail: ${ }^{\text {(a) }}$ vinicius.k99@ Gmail.com; ${ }^{(b)}$ celiaalvesgeo@globo.com; ${ }^{(c)}$ willtmt15@gmail.com, (d)josiane_bernardo05@hotmail.com)
\end{abstract}

\section{EIXO: BACIAS HIDROGRÁFICAS E RECURSOS HÍDRICOS: ANÁLISE, PLANEJAMENTO E GESTÃO}

\begin{abstract}
Resumo
Apesquisa teve por objetivo levantar as características ambientais e a evolução espaço temporal das feições morfológicas do corredor fluvial nos anos de 1984 e 2016. Para caracterização ambiental foi utilizado o relatório do projeto RADAMBRASIL folha SE.21 Corumbá e parte da folha SE.20, para a vetorização das feições osoftware ArcGis 10.2.1 ® a partir de imagens do satélite LANDSAT 5 e8. A área situasena Planície Fluvial do rio Paraguai, composto por sedimentos da Formação Pantanal, com solo GleissoloHáplico (Tb eutrófico) e vegetação do tipo Floresta Aluvial.Em 1984 foram registradas 5 lagoas, 1 furado, 7 baías, 3 ilhas, 3 bancos de sedimentos laterais e 1 central. No ano de 2016 foram verificadas apenas 11 lagoas, 4 baías e o surgimento de 3, 2 novas ilhas, 2 bancos de sedimentos laterais e o surgimento de 7, o banco central deixou de existir e surgiram 2 novos.
\end{abstract}

Palavras-chave:Paisagem; ambientes fluviais; pantanal;antropização.

\section{INTRODUÇÃO}

A análise visual de uma paisagem e/ou de agentes formadores da paisagem pode ser executada qualitativamente, à medida que se observam e se identificam as feições morfológicas do terreno, utilizando para isso os elementos de interpretação que são encontrados na imagem ou cena (PRICHOA et. al, 2014). Por possuir um caráter integrador entre o comportamento das condições naturais e das atividades humanas nelas desenvolvidas, como assim deduziu Cunha e Guerra (2009), a bacia hidrográfica possui grande importância nos estudos geográficos.

O rio Paraguai nasce no planalto central e após curto percurso penetra no pantanal, drena terrenos dos estados de Mato Grosso e Mato Grosso do Sul. Em certos trechos separa o Brasil da Bolívia e Paraguai, com 2.070 km de extensão abrange a área de 368.000 km² (CUNHA, 2009).

Conforme Cunha (2008, p.227) a quantidade de água que alcança o canal expressa o escoamento fluvial, que é alimentado pelas águas superficiais e subterrânea e a proporcionalidade 
entre estas fontes é definida pelo clima, solo, rocha, declividade e cobertura vegetal e que para Riccominiet al (2009), são esses os fatores que controla a morfologia dos canais fluviais.

A Planície do rio Paraguai recebe grande influência do clima, os pulsos de inundação contribuem diretamente para a manutenção da planície através do aporte de água, sedimentos e nutrientes, e também para o surgimento de diversas feições na planície, como as baias e as lagoas (SANTANA, 2013).

De acordo com Silva et. al. (2012), no Pantanal de Cáceres, o rio Paraguai com sua planície de inundação associado com os processos de sedimentação colaboram para a evolução fluvial. Os sedimentos depositados podem dificultar o escoamento da água, comprometer a navegabilidade, alterar a biodiversidade, gerando, assim, vários problemas ambientais,sociais e econômicos. Identificar as características ambientais e analisar a evolução das feições morfológicas propicia conhecer e compreender o funcionamento do sistema fluvial no segmento analisado.

Sendo assim o estudo tem por objetivo apresentar as características ambientais e a evolução espaço temporal das feições morfológicas do corredor fluvial do rio Paraguai entre a foz do córrego Jacobina e a baía dos Pestiados, Cáceres - Mato Grosso nos anos de 1984 e 2016. 


\section{MATERIAS E MÉTODOS}

2.1. Área de Estudo

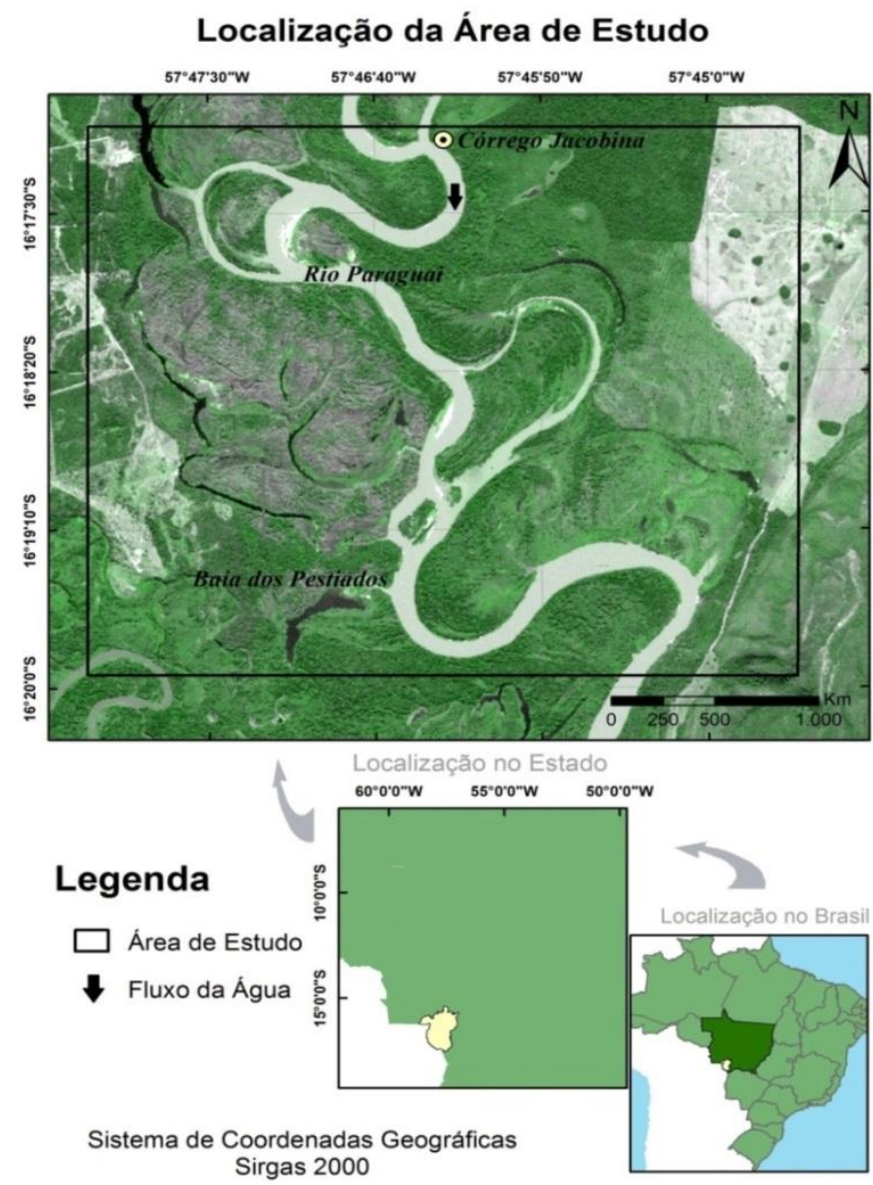

Figura 01: Localização da área de estudo.

A área de estudo compreende a um quadrante de $33,772 \mathrm{~km}^{2}$ que tem como referência um segmento do rio Paraguai, que se inicia próximo da foz do córrego Jacobina à foz da baia dos Pestiados (16 $17^{\circ} 8.63^{\prime \prime}$ à $16^{\circ} 19^{\prime} 30.00^{\prime \prime}$ de latitude $\mathrm{S}$ e $57^{\circ} 46^{\prime} 21.70^{\prime \prime}$ à $57^{\circ} 46^{\prime} 33.00^{\prime \prime}$ de longitude Oeste)no município de Cáceres-MT (Figura 01).

\subsection{Metodologia}

O trabalho Consistiu basicamente na etapa de Gabinete, sendo que foi realizado levantamento bibliográfico com artigos, livros, teses, dissertações e demais produções de cunho cientifico embasado na temática.Para caracterização ambiental (geologia, geomorfologia, solo e vegetação) da área foi utilizado o relatório do projeto RADAMBRASIL folha SE.21 Corumbá e parte da folha SE.20 (1982). 


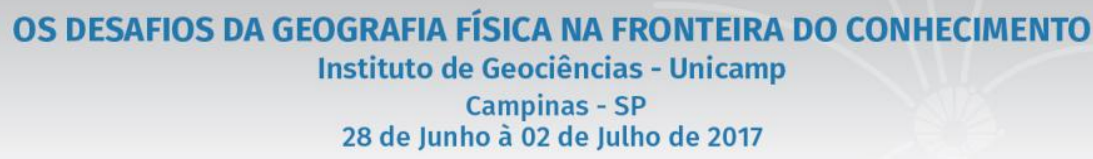

A mudança espaço-temporal das feições morfológicas assim como em Silva (2015) foram tratadas e analisadas pelo software ArcGis 10.2® a partir de imagens do satélite LANDSAT 5 TM (imagens de 1984)eLandsat 8 (imagens de 2016), órbita/ponto 227/071, ambas imagens do período de estiagem, adquiridos pelo catálogo do Instituto Nacional de Pesquisas Espaciais (INPE). A composição colorida foi efetuada nas bandas 6,5 e 4 , e banda 8 para aumentar a resolução na imagem (ferramenta Pan Sharpen) de 2016 e bandas 543 na imagem de 1984, onde os limites entre o solo e a água são mostrados mais claramente, sendo possível a vetorização das feições. As feições encontradas foram classificadasem ilhas, banco de sedimentos, baia e lagoas. As tabelas da área em $\mathrm{Km}^{2}$ foram calculados pela função Calculate Geometry2 no software ArcGis 10.2.

\section{RESULTADOS E DISCUSSÃO}

\subsection{Caracterização Ambiental da Área de Estudo}

O Clima predominante na área de estudo é considerado quente estacionalmente úmido e como definiu Souza (2004), para o Pantanal Mato-Grossense adistribuição da precipitação apresenta dois períodos bem definidos, isto é,época de chuvas intensas (outubro a abril) e período de estiagem (maio a setembro).

A área está situada na Planície Fluvial do rio Paraguai, sendo uma área plana resultante de acumulação fluvial periodicamente alagada pertencente à unidade de planícies e Pantanais Matogrossenses (RADAMBRASIL, 1982), que segundo Souza et al. (2013), apresenta uma variedade de formas geomorfológicas, que podem ser denominadas como positivas e negativas no terreno.

Quanto à geologia observou-se a ocorrência dos sedimentos da Formação Pantanal, do período Quaternário(RADAMBRASIL, 1982),, classificados em três diferentes níveis para a Formação Pantanal. O primeiro, topograficamente mais elevado, seria constituído por areia inconsolidada, de granulometria fina a média, intercalada por materiais síltico-argilosos. O segundo nível seria formador dos terraços aluviais sub-recentes, constituídos por silte, argila e areia fina. O último nível, constituído por uma planície mais rebaixada, teria como formadores os depósitos irregulares sílticoargilosos e grosseiros, depositados recentemente pelo rio Paraguai.

Quanto ao tipo de solo, registrou-se a ocorrência de GleissoloHáplico (Tb eutrófico)(RADAMBRASIL, 1982),estes são solos rasos, pouco desenvolvidos, orgânico-minerais, com características de locais planos e abaciados, sujeitos a alagamentos constantes ou periódicos, marcados por uma série de terraços e planícies fluviais e recobertos por vegetação de várzea. A ocorrência deste solo de baixa impermeabilidade dificulta infiltração da água contribuindo para manter a inundação por maior período (RADAMBRASIL, 1982; JACOMINE et. al., 1995). 


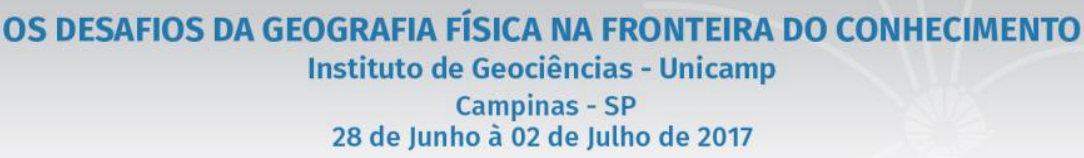

A cobertura vegetal contempla a Floresta Aluvial (mata ciliar)(RADAMBRASIL, 1982). Esta formação florestal ribeirinha é diversificada e suas principais características variam de acordo com sua localização na formação aluvial. São vegetações de pequeno porte, adaptáveis ao encharcamento do solo durante o período de cheia.

\subsection{Evolução Espaço/Temporal das Feições Morfológicas nos anos de 1984 a 2016}

O rio Paraguai no segmento analisado é meandrante com índice de sinuosidade de 1,76, podemos observar mudanças significativas ocorridas no canal e no corredor fluvial e nas feições morfológicas. Grande parte dessas mudanças ocorreu e ocorrem de forma natural em função de seu padrão, geralmente de forma equilibrada, principalmente as relacionadas com a deposição de sedimentos. Mas na área em questão, notamos que a atividade humana, como por exemplo, o uso de embarcações para pesca, esporte e recreio, pode serum dos principais agentes que intensificou e condicionou o surgimento e aumento dos bancos de sedimentos, a partir das ondas que essas embarcações criam, promovendo a erosão das margens e consequentemente o acumulo de sedimentos no canal.

Bindandi (2014) considerou que embora a navegação tenha sido um fator importante para desenvolvimento da cidade de Cáceres, a evolução e a quantidade das embarcações nas últimas décadastambém tem sido um dos principais agentes que vem alterando o processo natural da sedimentação e da morfologia do canal do rio Paraguai. A pecuária, também se concretiza como uma atividade promotora de degradação ambiental e em 1984 ocupava, 20,65\%, e em 2016 aumentou para $28,19 \%$ da área estudada(figura 02).

Ocorreram modificações no canal principal do rio Paraguai, de ordem numérica e morfológica, em 1984 ocupava uma área de 1,940 km² e regrediu para 1,701 km² em 2016 (tabela I). Na morfologia houve uma importante alteração natural no canal, em 1984, com rompimento do colo de um dos meandros, formou-se um furado (figura 02 e tabela I) de $0,151 \mathrm{~km}^{2}$ que em 2016 evoluiu para canal principal.

Em relação às baías, não houve o desaparecimento de nenhuma, mas a união de quatroque resultou na formação de novas baías. Em 1984 (Figura 02e tabela I), tinha sete baias, e em 2016 surgiram três novas, a nova baía 01 originada da união da baía 04 com a baía 05 , a nova baía 02 (baía dos Pestiados) que surgiu do encontro da lagoa 04 com o rio Paraguai e a nova baia 03, que como explicado anteriormente, foi um pouco mais complexa, originada a partir da transformação do furado 01 em canal principal, que fez com que surgisse uma nova baía que se uniu com a baía 03 e baía 07. 


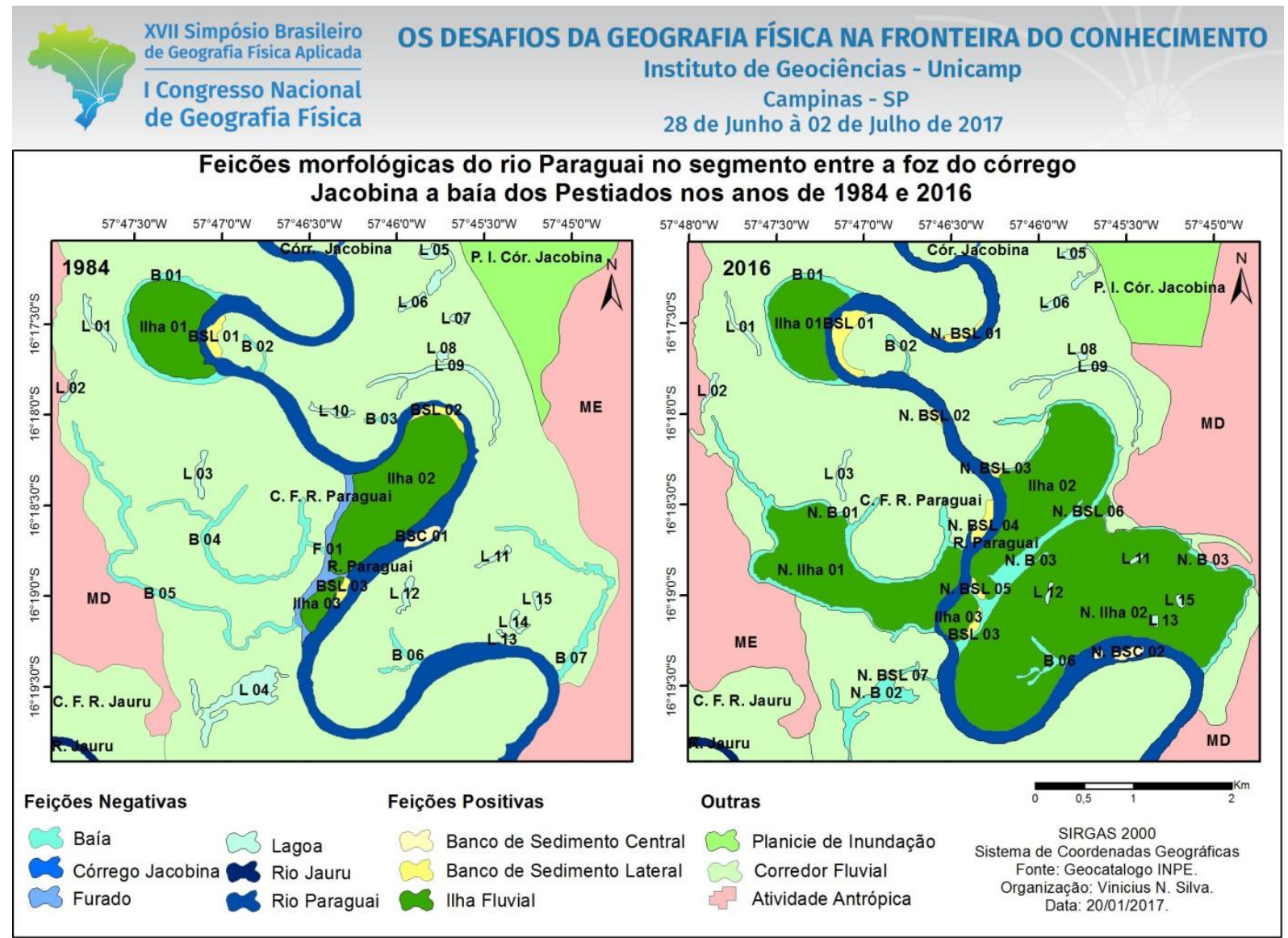

Figura 02: Feições morfológicas do rio Paraguai no segmento entre a foz do córrego Jacobina a foz da baía dos

Pestiados no anos de 1984 e 2016.

A lagoa (Figura 02 e tabela I) foi a única feição que não registrou novos surgimentos, que pode estar relacionado com a própria perda de área do corredor fluvial (de 24,239 $\mathrm{km}^{2}$ para 23,155 $\mathrm{km}^{2}$ - tabela I) para a pecuária e consequentemente o aumento de sedimentos que acelerou o processo de comaltação, sendo que em 1984 foram registradas quinze lagoas, e em 2016 três deixaram de existir (lagoa 07, 10 e 15) e uma (lagoa 04) evoluiu para baía (nova baía 02/baía dos Pestiados). E notasse ainda que em relação a área das lagoas, somente a lagoa 02 que registrou um pequeno acréscimo, e as demais regrediram ou conservaram seu valor.

Foram identificados em 1984, três bancos de sedimentos laterais e um central, sendo que em 2016, pela fixação da vegetação, um banco lateral e um central deixaram de existir, e em contra partida, surgiram sete novos bancos de sedimentos laterais (dois deles localizados em baias) e dois bancos centrais, que pode ser justificado como sendo efeito das atividades antrópicas mencionadas (figura 02 e tabela II). 
XVII Simpósio Brasileiro de Geografia Fisica Aplicada

I Congresso Nacional de Geografia Física

\section{OS DESAFIOS DA GEOGRAFIA FÍSICA NA FRONTEIRA DO CONHECIMENTO \\ Instituto de Geociências - Unicamp \\ Campinas - SP \\ 28 de Junho à 02 de Julho de 2017}

Tabela I: Feições Negativas (área $\mathrm{em} \mathrm{km}^{2}$ ) do corredor fluvial do rio Paraguai no segmento entre a foz do córrego Jacobina a foz da baía dos Pestiados em Cáceres -MT.

\begin{tabular}{|c|c|c|}
\hline Feição & $\begin{array}{c}\text { Área }\left(\mathbf{k m}^{2}\right) \\
1984\end{array}$ & $\begin{array}{c}\text { Área }\left(\mathrm{km}^{2}\right) \\
2016\end{array}$ \\
\hline Lagoa 01 & 0,037 & 0,031 \\
\hline Lagoa 02 & 0,017 & 0,022 \\
\hline Lagoa 03 & 0,029 & 0,029 \\
\hline Lagoa 04 & 0,215 & ------ \\
\hline Lagoa 05 & 0,065 & 0,038 \\
\hline Lagoa 06 & 0,020 & 0,020 \\
\hline Lagoa 07 & 0,010 & ------ \\
\hline Lagoa 08 & 0,009 & 0,007 \\
\hline Lagoa 09 & 0,103 & 0,086 \\
\hline Lagoa 10 & 0,021 & ------ \\
\hline Lagoa 11 & 0,018 & 0,007 \\
\hline Lagoa 12 & 0,026 & 0,009 \\
\hline Lagoa 13 & 0,007 & 0,007 \\
\hline Lagoa 14 & 0,019 & ------ \\
\hline Lagoa 15 & 0,012 & 0,009 \\
\hline Furado 01 & 0,151 & ----- \\
\hline Baía 01 & 0,147 & 0,110 \\
\hline Baía 02 & 0,017 & 0,018 \\
\hline Baía 03 & 0,014 & ----- \\
\hline Baía 04 & 0,185 & ------ \\
\hline Baía 05 & 0,214 & ------ \\
\hline Baía 06 & 0,037 & 0,044 \\
\hline Baía 07 & 0,144 & ------ \\
\hline Nova Baía 01 & ------ & 0,359 \\
\hline Nova Baía 02 & ------ & 0,186 \\
\hline Nova Baía 03 & ------ & 0,457 \\
\hline
\end{tabular}

Em 2016 foram registradas três ilhas fluviais (Ilha 01: formada pela separação do canal principal com a baia do tuiuiú; Ilha 02: formada pela separação do furado $01 \mathrm{com}$ o canal principal; e Ilha 03 que formou-se a partir da ilha 02 próximo ao encontro do furado com o canal principal), em 2016 surgiram duas novas ilhas fluviais (tabela II), a partir da união de duas baías (Nova ilha 01:união da baía 04 com a baía 05 e Nova ilha 02: um pouco mais complexa, originada a partir da transformação do furado 01 em canal principal, que fez com que surgisse uma nova baía que se uniu com a baía 03 e baía 07, formando a nova baía 03, conhecida como baía do Jatobá).(figura 02 e tabela II).

Tabela II: Feições Positivas (área em $\mathrm{km}^{2}$ ) do corredor fluvial do rio Paraguai no segmento entre a foz do córrego Jacobina a foz da baía dos Pestiados em Cáceres -MT.

\begin{tabular}{lcc}
\hline Feição & Área $\left(\mathrm{km}^{2}\right)$ & Área $\left(\mathbf{k m}^{2}\right)$ \\
& 1984 & 2016 \\
\hline
\end{tabular}




\begin{tabular}{|lll}
\hline Ilha 01 & 0,658 & 0,556 \\
\hline Ilha 02 & 1,124 & 1,202 \\
\hline Ilha 03 & 0,110 & 0,113 \\
\hline Nova Ilha 01 & ----- & 1,226 \\
\hline Nova Ilha 02 & ----- & 3,367 \\
\hline B. S. Lateral 01 & 0,046 & 0,096 \\
\hline B. S. Lateral 02 & 0,039 & ----- \\
\hline B. S. Lateral 03 & 0,022 & 0,023 \\
\hline Novo B. S. Lateral 01 & ----- & 0,006 \\
\hline Novo B. S. Lateral 02 & ------ & 0,012 \\
\hline Novo B. S. Lateral 03 & ----- & 0,009 \\
\hline Novo B. S. Lateral 04 & ----- & 0,041 \\
\hline Novo B. S. Lateral 05 & ----- & 0,014 \\
\hline Novo B. S. Lateral 06 & ----- & 0,005 \\
\hline Novo B. S. Lateral 07 & ----- & 0,006 \\
\hline B. S. Central 01 & 0,039 & ----- \\
\hline Novo B. S. Central 01 & ----- & 0,006 \\
\hline Novo B. S. Central 02 & ----- & 0,029 \\
\hline
\end{tabular}

\section{CONSIDERAÇÕES FINAIS}

As feições morfológicas descritas neste trabalho surgiram em função das características ambientais (geomorfologia: Planície Fluvial do rio Paraguai; geologia: sedimentos da Formação Pantanal; solo: GleissoloHáplico (Tb eutrófico); e vegetação: Floresta Aluvial - mata ciliar) da área e relacionado com o clima quente estacionalmente úmido. Podemos considerar,que a dinâmica de sua paisagem pode estar sendo alterada pelas atividades antrópicas, que pode ser justificada pelosurgimento dos bancos de sedimentos que podem está relacionada principalmente com o fluxo de embarcações, que através das ondas geradas, promovem erosão e deposição no canal.

Embora seja bastante dificultoso, haja visto que a qualidade da imagem não facilite a identificação e analise da paisagem, o resultado adquirido a partir da vetorização das imagens do satélite Landsat 5 e 8 mostrou-se bastante satisfatório, pois possibilitou a compreensão e direcionou a discussão para que entendêssemos o funcionamento do sistema fluvial no corredor fluvial analisado. 


\section{REFERÊNCIAS BIBLIOGRÁFICAS}

Brasil. Ministério das Minas e Energia, Secretária-Geral. Projeto RADAMBRASIL: levantamentos dos recursos naturais, Folha SE 21 Corumbá e parte da SE 20. Rio de Janeiro: Ministério de Minas e Energia- Secretaria Geral, 1982.

BINDANDI, N. M.. Evolução da navegação, morfologia e sedimentação no rio Paraguai no município de Cáceres, Mato Grosso, Brasil. Dissertação (Mestrado em Ciências Ambientais) Cáceres: UNEMAT, 2014, 125 f.

CUNHA, S.B. Geomorfologia Fluvial. In: CUNHA, S. B.; GUERRA, A.J.T. Geomorfologia, uma atualização de bases e conceitos. 8 ed.- Rio de Janeiro: Bertrand Brasil, 2008.

CUNHA, S. B. Bacias Hidrográficas In: CUNHA, S.B.; GUERRA, A. J. T (org.) Geomorfologia do Brasil. $5^{\text {a }}$ ed. Rio de Janeiro: Bertrand Brasil, 2009.

CUNHA, S.B.; GUERRA, A.J.T. Degradação Ambiental. In: GUERRA, A.J.T. e CUNHA, S.B. da. (orgs). Geomorfologia e Meio Ambiente. $7^{\mathrm{a}}$ ed. - Rio de Janeiro. Bertrand Brasil, 2009. 396 p.

JACOMINE, P. K. T. et al. Guia para identificação dos principais tipos de solos de

Mato Grosso. Cuiabá: PNUD-PRODEAGO, 1995. 50 p.

PRICHOA, C. E.; RIBEIRO, S. R. A.; HOLGADO, P. M.. Aplicação da análise visual em duas unidades de paisagem da bacia hidrográfica do rio Pitangui, PR, mediante processamentos digitais. Terr@Plural, Ponta Grossa, v.8, n.1, p. 185-201, jan/jun. 2014.

RICCOMINI, C. et al. Processo Fluviais e Lacustres e seus registros. In: TEIXEIRA, W. et al. Decifrando a terra.2 ed.- São Paulo: Companhia Editora Nacional, 2009.

SANTANA, M. F.. Análise de séries temporais de vazão e precipitação na bacia do rio Paraguai. Revista GeoPantanal . UFMS/AGB . Grupo de Pesquisa Pantanal Vivo . Corumbá/MS . 8(14): 67-89 . Jan./Jun. 2013.

SILVA, E. S. F.; SOUZA, C. A.; LEANDRO, G. R. S.; ANDRADE, L. N. P. S.; GALBIATI, C.. Evolução das feições morfológicas do rio Paraguai no Pantanal de Cáceres - Mato Grosso. Revista Brasileira de Geomorfologia, v.13, n.4, (Out-Dez) p.435-442, 2012.

SILVA, C.. Análise da evolução espaço/temporal. Das feições morfológicas e transporte atual de sedimento no rio Paraguai entre a foz do rio Jauru e a ilha Tucum, Cáceres - Mato Grosso. Cristiane da Silva. Cáceres/MT. (Trabalho de Conclusão de curso de Geografia) Universidade do Estado de Mato Grosso: Campus Cáceres, 2015.

Souza, C. A.. Dinâmica do corredor fluvial do rio Paraguai entre a cidade de Cáceres e a Estação Ecológica da ilha de Taiamã - MT. Tese (Doutorado em Geografia) Universidade Federal do Rio de Janeiro. Rio de Janeiro. 2004.

SOUZA, C. A. et al. Sedimentação no rio Paraguai e no baixo curso dos tributários Sepotuba, Cabaçal e Jauru, Mato Grosso, Brasil. In: 14 ENCONTRO DE GEÓGRAFOS DA AMÉRICA LATINA (Egal Peru), 2013. 